\title{
Spontaneous coronary dissection associated with systemic lupus erythematosus
}

\author{
Disección coronaria espontánea asociada a lupus eritematoso sistémico
}

Manuel I. García-Sánchez ${ }^{*}$, Jorge Carrillo², Yuyi Montero ${ }^{3}$, and Daniel Senisca/4

${ }^{1}$ Department of Clinical Cardiology, Universidad Nacional Autónoma de México (UNAM); ${ }^{2}$ Department of Interventional Cardiology, Cardiovascular Hemodynamics Unit; ${ }^{3}$ Department of Cardiology and Echocardiography, Coronary Intensive Care Unit. Centro Médico Nacional La Raza "Dr. Antonio Fraga Mouret"; ${ }^{4}$ Department of Internal Medicine, Centro Médico ABC, UNAM. Mexico City, Mexico

\begin{abstract}
A 29-year-old female with a medical history of systemic lupus erythematosus, diagnosed 15 years earlier, presents with lupus nephritis, currently on peritoneal dialysis. She had myopericarditis in 2012 and is currently on immunosuppressants. The patient began with exertional dyspnea and angina 2 weeks before admission. An echocardiogram was performed, reporting severe mitral and tricuspid insufficiency. Afterward, the patient presented with resting angina associated with an adrenergic and vagal response. Initially, rheumatology ruled out autoimmune activity caused by lupus. We performed a coronary angiogram based on clinical presentation, EKG changes and biomarkers, finding a trivascular coronary artery disease classified as a Markis I coronary artery ectasia and a coronary dissection of the ramus intermedius and the circumflex, posterior to the first obtuse marginal artery. Cardiothoracic surgery considered intervention with a coronary bridge posterior to the dissection of the intermedius ramus artery, marginal obtuse and posterolateral artery, as well as a mitral valve replacement and a tricuspid valve repair. Coronary dissection is more common in women (70\%), clinical presentation varies from unstable angina to sudden death. In lupus nephritis, it is an uncommon form of extra renal vasculitis. Treatment depends on the number of arteries affected, as well as the hemodynamic state of the patient. It is imperative to individualize treatment options.
\end{abstract}

Key words: Coronary dissection. Coronary ectasia. Lupus nephritis. Vasculitis.

\section{Resumen}

Se presenta el caso de una paciente de 29 años con antecedente de lupus eritematoso sistémico diagnosticado 15 años antes, que desarrolló nefropatía lúpica actualmente en diálisis peritoneal, cuadro de miopericarditis en 2012 y bajo tratamiento inmunosupresor. Inició con deterioro de su clase funcional por disnea y angina 2 semanas previas al ingreso. Se le realizó ecocardiograma, el cual reportó insuficiencias mitral y tricuspídea graves. Posteriormente presentó angina en reposo asociada a descarga adrenérgica y vagal. A su ingreso se descarta actividad lúpica por reumatología. Por presentación clínica, cambios en electrocardiograma y biomarcadores, se realizó cateterismo cardiaco, que reportó enfermedad coronaria trivascular con ectasia coronaria Markis I y disección coronaria de ramo intermedio y circunfleja posterior a la primera marginal obtusa. Se consideró por el servicio de cirugía cardiotorácica realizar intervención con puente coronario posterior a disección del ramo intermedio, marginal obtusa y posterolateral, así como cambio valvular mitral y plastia tricuspídea. La disección coronaria espontánea es más frecuente en las mujeres (70\%); puede presentarse como angina inestable y hasta

\section{Correspondence:}

*Manuel I. García-Sánchez

E-mail: meny.nem@gmail.com license (http://creativecommons.org/licenses/by-nc-nd/4.0/).

Date of reception: 29-01-2020

Date of acceptance: 21-08-2020

DOI: 10.24875/ACME.M21000180
Available online: 25-05-2021

Arch Cardiol Mex (Eng). 2021;91(1):104-109 www.archivoscardiologia.com 
como muerte súbita. La asociación con lupus eritematoso sistémico es poco frecuente, con una incidencia del $0.42 \%$. En la nefropatía lúpica es una manifestación poco frecuente de vasculitis extrarrenal. El tratamiento de elección depende del número de vasos afectados y del estado hemodinámico, por lo que es necesario individualizarlo para cada paciente.

Palabras clave: Disección coronaria. Ectasia coronaria. Nefropatía lúpica. Vasculitis.

\section{Introduction}

Spontaneous coronary artery dissection (SCAD) is an uncommon diagnosis of exclusion in acute coronary artery syndromes, with a reported prevalence $0.1-1.1 \%$, and most reports being in people younger than 50 years and in women in the peripartum period ${ }^{1,2}$. It is defined as a spontaneous separation of the coronary arterial wall that is not iatrogenic or caused by trauma, and the term excludes atherosclerotic etiology ${ }^{3}$. Two hypotheses are currently accepted for its pathogenesis: intimal tear with subsequent formation of intramural hematoma and medial layer hemorrhage initiated by lesion in the vasa vasorum ${ }^{3,4}$. Clinical presentation varies from acute coronary syndrome in all its variants to heart failure and even sudden death ${ }^{4}$. In general, there is a predisposing arterial disease in the background and a triggering stressor. The first case includes fibromuscular dysplasia (most dominant association), associated with pregnancy, connective tissue diseases, systemic inflammatory diseases, hormone therapy or idiopathic causes. Regarding the predisposing stressors, intense stress and exercise, childbirth, activities with intense Valsalva and some addictive drugs, among others, stand out. In case reports, autoimmune inflammatory diseases have been associated with SCAD in $<1 \%$ of cases, although this is probably an underestimation; nevertheless, chronic inflammation caused by vasculitis has been proposed as a predisposing factor ${ }^{4,5}$.

There are differences in terms of presentation, evolution, and prognosis in SCAD of atherosclerotic and non-atherosclerotic etiology, mainly due to the treatment it entails, which is why early and accurate diagnosis is required ${ }^{6}$. Coronary angiography has been the first-line method in the diagnosis of SCAD, but due to limitations in the evaluation of frames per second and the lack of higher structural definition of the vessel in question; currently, it is possible for intracoronary images to be obtained during invasive angiography by means of intravascular ultrasound (IVUS) and optical coherence tomography (OCT), which complement the diagnosis and management of SCAD?.

Therapeutic modalities have been proposed based on numerous case series. Ideally, risk stratification according to clinical and imaging findings supports individualized management, from conservative treatment to surgery with aortocoronary bypass ${ }^{3,7}$.

We present the case of a young woman with systemic lupus erythematosus presenting with unstable angina and decompensated heart failure, in whom initially lupus activity was suspected as the cause of decompensation and, at her in-hospital evolution, the angiographic finding of spontaneous coronary artery dissection in more than one vessel was made.

\section{Case presentation}

29-year-old woman with a history of systemic lupus erythematosus on treatment with prednisone, lupus nephropathy on renal replacement therapy with peritoneal dialysis and a history of acute myopericarditis in 2012.

Current condition started with functional class deterioration due to dyspnea and angina 2 weeks before her admission, which was progressive on high- to low-intensity exertion. On initial echocardiogram, severe mitral tricuspid regurgitation was concluded, as well as biatrial dilation without thrombi, with Grade II diastolic dysfunction, left ventricular ejection fraction of $35 \%$, with generalized hypokinesia, and preserved right ventricular systolic function (Fig. 1). At her admission, the rheumatology department ruled out lupus activity. Subsequently, during hospitalization, she had an episode of resting angina associated with adrenergic and vagal response, which worsened dyspnea. An electrocardiogram was performed during the episode, which showed normal sinus rhythm, PR and QT intervals within normal ranges, data indicative of septal hypertrophy and left ventricle with positive acuminated symmetric $T$ waves in precordial leads. Specific biomarkers showed a troponin I value of $0.24 \mathrm{ng} / \mathrm{ml}$, raising the suspicion of an underlying ischemic disorder (Fig. 2). For this reason, she was evaluated by the hemodynamic interventional cardiology department, which justified the performance of heart catheterization, in which trivascular coronary artery disease with Markis type I coronary artery ectasia and coronary dissection of the ramus intermedius and distal to first obtuse marginal branches of the circumflex artery was reported (Fig. 3). The cardiothoracic surgery department considered the 


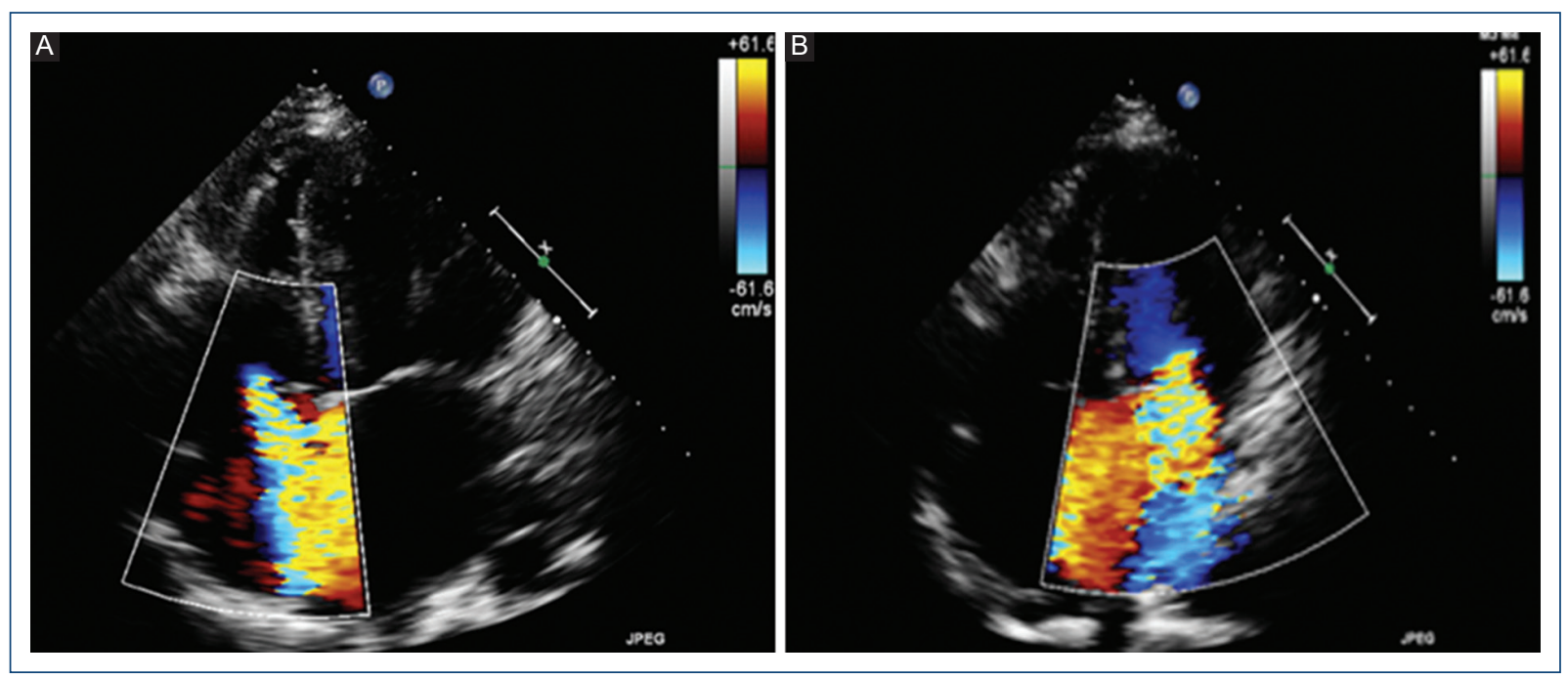

Figure 1. A: Echocardiogram, four-chamber apical image, showing severe tricuspid regurgitation with 10.2-mm vena contracta. Right atrial area is $21 \mathrm{~cm}^{2}$. B: Echocardiogram, four-chamber apical image, showing severe mitral regurgitation with a regurgitant orifice area of $0.4 \mathrm{~cm}^{2}$. Regurgitant volume is $125 \mathrm{~mL}$, and in the left atrium it is $42 \mathrm{~mL} / \mathrm{m}^{2}$.

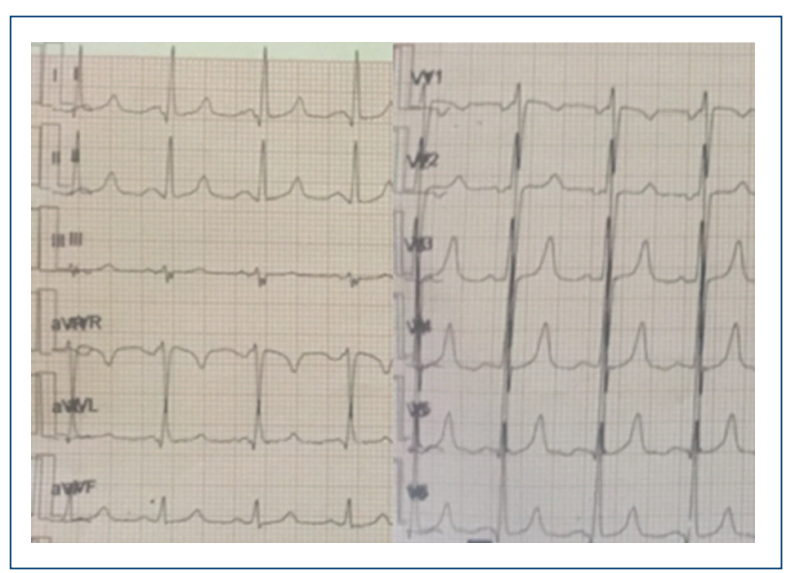

Figure 2. 12-lead electrocardiogram showing normal sinus rhythm, $10^{\circ}$ QRS axis, P wave $140 \mathrm{~ms}$, PR $200 \mathrm{~ms}$, QRS $100 \mathrm{~ms}$, increased voltage in precordial leads, Cornell 25 $\mathrm{mm}$ and $10-\mathrm{mm}$ acuminate symmetric $T$ waves, suggestive of subendocardial ischemia.

performance of coronary artery bypass graft (CABG) surgery after dissection of the ramus intermedius, obtuse marginal and posterolateral branches, as well as mitral valve replacement and tricuspid valve repair.

\section{Discussion of the case}

SCAD was first described in 1931 in the autopsy of a 42-year-old woman and, since then, multiple case reports and short reviews have been made on the subject, but there are still no specific clinical guidelines available ${ }^{7-9}$. SCAD consists of the detachment of two of the three layers of the arterial wall to create a false lumen, usually between the tunica media and the intima. It is more common in women $(70 \%)$, even in relation to pregnancy $(30 \% \text { of cases })^{10}$, and it occurs as angina $(95.9 \%)$ or even as sudden death $(<0.5 \%)^{10-13}$. Its association with systemic lupus erythematosus is rare, with a incidence of $0.42 \%$, with risk being three times higher than in the normal population ${ }^{12}$. From the point of view of lupus nephropathy, it is a rare manifestation of extra-renal vasculitis. Classically, SCAD etiology was regarded as postpartum or peripartum, atherosclerotic and idiopathic; however, with the development of new imaging methods, its association with Ehlers-Danlos and Marfan syndromes, fibrodysplasia, use of cocaine or oral contraceptives, and extreme exercise has been described. To classify its etiology, Saw et al. ${ }^{3}$ propose four groups: (1) associated with connective tissue diseases, (2) patients with atherosclerosis or vasculitis, (3) peripartum, and (4) idiopathic ${ }^{3,12-14}$

Initial diagnosis is made with invasive coronary angiography, which continues to be the first-line method; however, due to its limitations in lesion characterization and subsequent risk stratification, intracoronary imaging techniques, such as IVUS and OCT, have been proposed in the diagnostic and treatment algorithm. However, these are ideal studies, they are not essential 


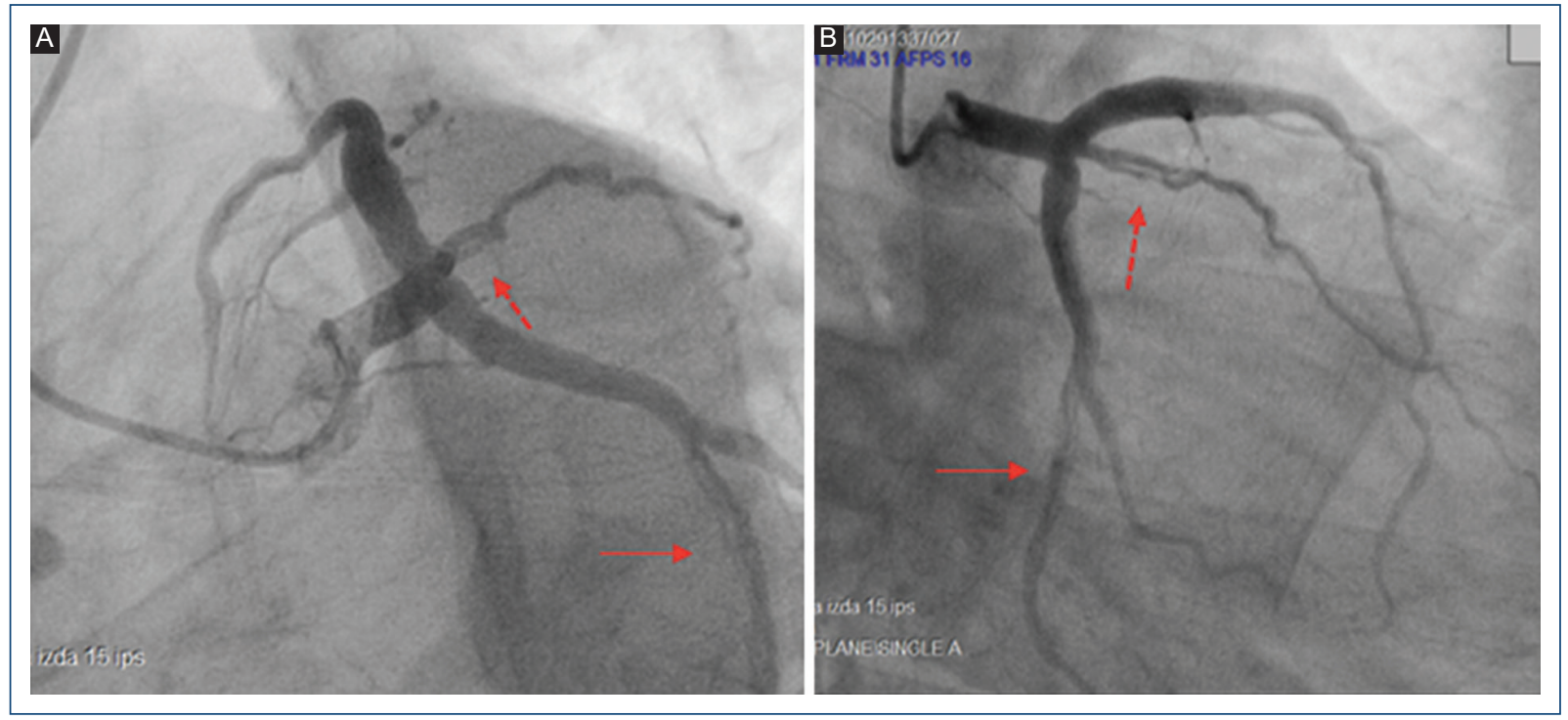

Figure 3. A: Coronary angiography, caudal left anterior oblique projection, showing a NHLBI type B of or Saw type 1 dissection of the ramus intermedius proximal segment (broad arrow); type B dissection of circumflex artery distal segment (thin arrow). B: Coronary angiography, left anterior oblique cranial projection, showing a NHLBI type B or Saw type 1 dissection of the ramus intermedius proximal segment (wide arrow) and type B dissection of the circumflex artery distal segment, with larger extension (thin arrow).

in clinical practice, since not all centers have these invasive imaging methods. Therefore, initial identification by coronary angiography takes prominence. Previously, the National Heart, Lung, and Blood Institute (NHLBI) established six types of coronary dissection (A-F). In this patient's case, we considered it to be type $B$ due to the double lumen separated by an area of radiolucency, with persistence after contrast washout. However, due to the overlapping of criteria with other conditions in the case of types $\mathrm{C}$ to $\mathrm{F}$, Saw et al. ${ }^{3}$ based on the numerous characterizations by intracoronary imaging, propose in their review three types in angiographic classification: (1) the pathognomonic lesion is the contrast staining of the arterial wall with multiple radiolucent lumens, and it occurs in $29 \%$ of cases; (2) diffuse lesions, typically $>30 \mathrm{~mm}$, without a visible dissection plane, which can result in complete occlusion of the vessel, and, in turn, are classified into two subtypes, A (segmental lesions) and B (lesions extended throughout the vessel), with $B$ being the most common (67.5\%); and (3) focal or tubular lesions suggestive of atherosclerotic stenosis and that generally require intracoronary imaging studies to confirm the diagnosis, which account for $3.4 \%$ of the cases ${ }^{3,14}$. As for the predominance of the affected vessel, the anterior descending artery is the most affected (34-42\%), compromising middle to distal segments, and in $<10 \%$ of cases, proximal segments. Multiple vessel dissection occurs in $9-19 \%$ of cases $4,5,15$. Nevertheless, the latter percentages are obtained from reviews that include all SCAD etiologies.

There are several management algorithms and, in this area, the main exponents on the subject, Saw et al. ${ }^{3}$ refer to a staggered diagnosis starting with coronary angiography, and according to the aforementioned clinical presentation, type 1 SCAD appearance should be objectively sought. If this type does not occur, identifying fine and diffuse stenosis, as described in type 2 SCAD, should be attempted; in this step, intravenous administration of nitroglycerin is suggested to perform IVUS or OCT, with the purpose to define the possibility of reassessment in 4-6 weeks. On the other hand, if those characteristics are not found, type 3 appearance, which simulates atherosclerotic lesions, should be sought and, for this approach, it will be essential to perform intracoronary imaging studies $3,4,7,15$. Regarding imaging modalities, OCT has the best resolution for defining intimal rupture, thrombus and intramural hematoma, and false lumen; however, due to a lower penetrance, it has higher difficulty for defining the extension of some intramural hematomas. Although there are obvious advantages, it is necessary to consider the risks 
of a coronary intervention, how to mechanically broaden the dissection with the catheter or hydraulically with contrast, and even the risk of thrombosis inserting a catheter entails should be considered ${ }^{16}$. Computed tomography angiography is not included among the decisions due to spatial limitation to identify lesions in distal vessels (which is the most commonly compromised area $)^{16,17}$. Regarding the patient of our clinical case, interpretation of the lesions could guide us toward type 1 common clinical appearance, with double lumen observed in the circumflex artery and ramus intermedius. The patient also started clinical presentation with unstable angina and heart failure decompensation, both high-risk factors for cardiovascular complications. Similarly, another key factor in terms of treatment possibilities is Markis type I coronary ectasia, which definitely modifies the possibility of percutaneous interventions and reminds us of the many considerations to have in mind with regard to drug treatment and the hemodynamic flow implications associated with revascularization of an ectatic vessel.

Optimal treatment is not yet established, as there are no randomized clinical trials on conservative management in comparison with revascularization strategies, and evidence is based on case series, where SCAD main etiology is atherosclerosis; therefore, in the case of our patient, it is necessary for the management to be individualized because, although an atherogenic background is not ruled out, clinical presentation points at different pathophysiological pathways. Thrombolysis is known to constitute a high risk factor due to the possibility for the hematoma to increase and for dissection ${ }^{15,17}$. Conservative management has been proposed in stable patients with low risk of complications and progression, based on reviews that report spontaneous resolution in 4-6 weeks in non-complex cases ${ }^{3,5-18}$. Percutaneous coronary intervention remains the first option for invasive management, although complications have been described up to $53 \%$ of cases, with surgical revascularization being required $4,15,17$. Furthermore, larger numbers of compromised vessels lean toward surgical management. Medical treatment can be considered in case adequate flow is observed on coronary angiography after acute presentation ${ }^{14-18}$. Due to this discrepancy, Saw et al. ${ }^{3}$ propose a dichotomized treatment algorithm based on baseline risk (high risk: acute or previous myocardial infarction, acute or previous stroke, stable coronary artery disease, peripheral arterial disease, and atrial fibrillation). If there are no risk factors, the option is conservative management with medical therapy (beta blockers, antiplatelet aggregation agents, renin-angiotensin axis blockers, etc.). When there is one or more factors present, the condition is considered as high risk and, subsequently, clinical presentation is considered (coronary trunk dissection, identified ongoing angina or ischemia, fibrillation or ventricular tachycardia, and cardiogenic shock); if there is an isolated trunk lesion, coronary percutaneous interventionism is the choice, and if proximal lesions in other vessels are added, CABG surgery is considered. The latter is also considered in case of hemodynamically stable ventricular fibrillation or tachycardia, or ongoing angina or ischemia identified in more than two vascular territories where, for any reason, performing percutaneous coronary intervention is not possible. On the other hand, if hemodynamic instability occurs, either in the presence of ventricular arrhythmias or in case of cardiogenic shock, improving the hemodynamic status is necessary through inotropism or ventricular mechanical assistance, among others $3,18,19$.

In the case of our patient, due to her comorbidity and medical history, direct classification at high-risk should be considered; the patient is known to have decreased ejection fraction, without cardiogenic shock or ventricular arrhythmias occurring during hospitalization. On coronary angiography, proximal dissection of the Ramus intermedius and circumflex artery was observed, although there was difficulty for stent implantation by percutaneous coronary intervention due to the presence of Markis type I coronary ectasia. Therefore, according to the algorithm, the performance of $C A B G$ surgery was justified.

\section{Conclusions}

This case is about a young woman who presented with various chronic complications of an autoimmune disease. Based on the described findings, an acute coronary syndrome was suspected at the time of angina and decompensation of her chronic heart failure, as well as based on the electrocardiogram and biomarkers data and, subsequently, the condition was corroborated by coronary angiography. It is a case with a retrospective analysis, where the angiographic finding occurred due to the protocol-based follow-up of chest pain, and with the interpretation of minimal changes in a reproducible diagnostic tool that is essential to every cardiologist, such as electrocardiogram. Interestingly, the acute ischemic changes reported in the electrocardiogram were correlated with a better prognosis in the post-operative period, since the identification of acute coronary syndrome without progression to infarction 
per se, allowed better adaptation for compensation mechanisms. As previously mentioned, the proposed management considered the valvular pathology that was found, the number of compromised vessels and the patient chronic comorbidity, taking into account the high risk of post-operative complications due to the requirement of immunosuppression, given the risk of systemic lupus erythematosus exacerbation. During the post-operative period, extubation was achieved at $36 \mathrm{~h}$. On her last evaluation, the patient was in New York Heart Association functional Class II, without angina, under anticoagulation and on periodical follow-up by the multi-disciplinary team.

Despite the high risks of surgical complications, initial lack of improvement with conservative treatment, as well as the probable risk of progression to cardiogenic shock, surgical intervention was considered to be the next step of management. It is highly likely that age and organ compensation mechanisms offered a favorable prognosis in CABG surgery.

SCAD is a diagnosis that should always be considered in young women with heart failure or acute coronary syndrome. Despite the lack of conclusive evidence, clinical judgment should always guide therapeutic management and, more importantly, when treatment is individualized.

\section{Funding}

This investigation has not received any specific grant from public, commercial, or non-profit sector agencies.

\section{Conflicts of interest}

None.

\section{Acknowledgments}

Material resources of the Instituto Mexicano del Seguro Social were made available for the preparation of this document. The authors express their appreciation to the authorities of the Department of Cardiology, to the Coronary Intensive Care Unit and to the Hemodynamics Department at Centro Médico Nacional La Raza, for allowing the use of material and personal resources to reach the correct diagnosis and treatment of the patients.

\section{Ethical disclosures}

Protection of human and animal subjects. The authors declare that no experiments were performed on humans or animals for this research.

Confidentiality of data. The authors declare that they have followed the protocols of their work center on the publication of patient data.

Right to privacy and informed consent. The authors declare that no patient data appear in this article.

\section{References}

1. Mortensen KH, Thuesen L, Kristensen IB, Christiansen EH. Spontaneous coronary artery dissection: a Western Denmark Heart Registry study. Catheter Cardiovasc Interv. 2009:74:710-7.

2. Hering D, Piper C, Hohmann C, Schultheiss HP, Horstkotte D. [Prospective study of the incidence, pathogenesis and therapy of spontaneous, by coronary angiography diagnosed coronary artery dissection.] Z Kardiol. 1998;87:961-70.

3. Saw J, Mancini GBJ, Humphries KH. Contemporary review on spontaneous coronary artery dissection. J Am Coll Cardiol. 2016;68:297 -312. [Published correction appears in J Am Coll Cardiol. 2016; 68:1606.]

4. Saw J, Aymong E, Sedlak T, Buller CE, Starovoytov A, Ricci D, et al. Spontaneous coronary artery dissection: association with predisposing arteriopathies and precipitating stressors and cardiovascular outcomes. Circ Cardiovasc Interv. 2014;7:645-55.

5. Kamran M, Guptan A, Bogal M. Spontaneous coronary artery dissection: case series and review. J Invasive Cardiol. 2008;20:553-9.

6. Franco C, Starovoytov A, Mancini GB, et al. Spontaneous resolution of LV dysfunction post SCAD: a case series. Paper presented at: SCAI 2015, May 69, 2015; San Diego, CA.

7. Saw J. Coronary angiogram classification of spontaneous coronary artery dissection. Catheter Cardiovasc Interv. 2014;84:1115-22.

8. Pretty HC. Dissecting aneurysm of coronary artery in a woman aged 42 : rupture. BMJ. 1931:1:667.

9. Tweet MS, Hayes SN, Pitta SR, Simari RD, Lerman A, Lennon RJ, et al. Clinical features, management, and prognosis of SCAD. Circulation. 2012;126:579-88.

10. Romero-Rodríguez N, Fernández-Quero M, Villa Gil-Ortega M, Urbano del Moral JA, Ballesteros Prada S, Díaz de la Llera L, et al. Disección coronaria espontánea y sus implicaciones pronósticas a largo plazo en una cohorte de 19 casos. Rev Esp Cardiol. 2010;63:1088-91.

11. Shamloo BK, Chintala R, Freedman AN, Potosky A, Malin J, Weiss Smith S. Spontaneous coronary artery dissection: aggressive vs conservative therapy. J Invasive Cardiol. 2010;22:222-8.

12. DeMaio SJ Jr, Kinsella SH, Silverman ME. Clinical course and long-term prognosis of spontaneous coronary artery dissection. Am J Cardiol. 1989;64:471-4.

13. Álvarez-Lario B, Álvarez-Roy L, Mayordomo-Gómez S, García-García JM Spontaneous coronary artery dissection in systemic lupus erythematosus: case-based review. Rheumatol Int. 2019;39:1821-7.

14. Aziz S. Spontaneous coronary artery dissection. E-Journal of Cardiology Practice. 2017;14(38). Disponible en: https://www.escardio.org/Journals/E-Journal-of-Cardiology-Practice/Volume-14/spontaneous-coronary-artery-dissection

15. Tweet MS, Eleid MF, Best PJ, Lennon RJ, Lerman A, Rihal CS, et al Spontaneous coronary artery dissection: revascularization versus conservative therapy. Circ Cardiovasc Interv. 2014;7:777-86.

16. Alfonso F, Paulo M, Gonzalo N, Dutary J, Jiménez-Quevedo P, Lennie V, et al. Diagnosis of spontaneous coronary artery dissection by optical coherence tomography. J Am Coll Cardiol. 2012;59:1073-9.

17. Saw J. Spontaneous coronary artery dissection. Can J Cardiol. 2013;29:1027-33.

18. Alfonso F, Bastante T, Rivero F, Cuesta J, Benedicto A, Saw J, et al. Spontaneous coronary artery dissection. Circ J. 2014;78:2099-110.

19. Lempereur M, Fung A, Saw J. Stent malapposition with resorption of intramural hematoma with spontaneous coronary artery dissection. Cardiovasc Diagn Ther. 2015;5:323-9. 